\title{
One to Find Them All: A General Route to $\mathrm{Ni}(\mathrm{I})-$ Phenolate Species
}

\section{Journal Article}

Author(s):

Bismuto, Alessandro (1); Müller, Patrick; Finkelstein Dobratz, Patrick (i); Trapp, Nils; Jeschke, Gunnar; Morandi, Bill

Publication date:

2021-07-21

Permanent link:

https://doi.org/10.3929/ethz-b-000494460

\section{Rights / license:}

Creative Commons Attribution-NonCommercial-NoDerivatives 4.0 International

\section{Originally published in:}

Journal of the American Chemical Society 143(28), https://doi.org/10.1021/jacs.1c03763

\section{Funding acknowledgement:}

184658 - Catalytic synthesis of unprotected amines and heterocycles (SNF) 


\title{
One to Find Them All: A General Route to Ni(I)-Phenolate Species
}

\author{
Alessandro Bismuto, Patrick Müller, Patrick Finkelstein, Nils Trapp, Gunnar Jeschke,* and Bill Morandi* \\ Cite This: J. Am. Chem. Soc. 2021, 143, 10642-10648 \\ Read Online
}

ABSTRACT: The past 20 years have seen an extensive implementation of nickel in homogeneous catalysis through the development of unique reactivity not easily achievable by using noble transition metals. Many catalytic cycles propose $\mathrm{Ni}(\mathrm{I})$ complexes as potential reactive intermediates, yet the scarcity of nickel(I) precursors and the lack of a general, non-ligand-specific protocol for their synthesis have hampered progress in this field of research. This has in turn also limited the access to novel, well-

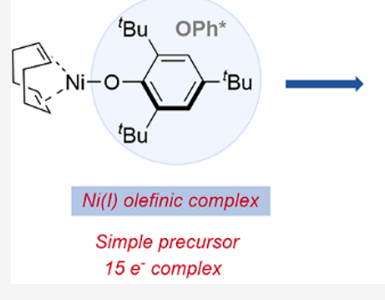

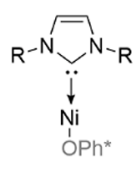
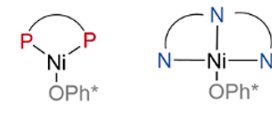

two-coordinate three-coordinate four-coordinate Simple precursor $5 e^{-}$complex Unified access to many new Ni(I) complexes defined $\mathrm{Ni}(\mathrm{I})$ species for the development of new catalytic reactions. Herein, we report a simple, general route to access a wide variety of $\mathrm{Ni}(\mathrm{I})$-phenolate complexes via an unusual example of an olefinic $\mathrm{Ni}(\mathrm{I})$ complex, $\left[\mathrm{Ni}(\mathrm{COD})\left(\mathrm{OPh}^{*}\right)\right]\left(\mathrm{COD}=1,5\right.$-cyclooctadiene, $\left.\mathrm{OPh}^{*}=\mathrm{O}\left({ }^{t} \mathrm{Bu}\right)_{3} \mathrm{C}_{6} \mathrm{H}_{2}\right)$. This route has proven to be highly efficient for several coordination numbers and ligand classes enabling access to the following complexes: $\left[\mathrm{Ni}(\mathrm{IPr})\left(\mathrm{OPh}^{*}\right)\right]\left(\mathrm{IPr}=1,3\right.$-bis$(2,6$-diisopropylphenyl)imidazol-2-ylidene $),\left[\mathrm{Ni}(\mathrm{dcype})(\mathrm{OPh})^{*}\right)$ (dcype = 1,2-bis $($ dicyclohexylphosphino)ethane), $\left[\mathrm{Ni}(\mathrm{dppe})\left(\mathrm{OPh}^{*}\right)\right]\left(\mathrm{dppe}=1,2\right.$-bis (diphenylphosphino)ethane), and $\left[\mathrm{Ni}(\right.$ terpy $\left.)\left(\mathrm{OPh}^{*}\right)\right]\left(\right.$ terpy $=2,2^{\prime}: 6^{\prime}, 2^{\prime \prime}$ terpyridine $)$. Moreover, reacting $\left[\mathrm{Ni}(\mathrm{dcype})\left(\mathrm{OPh}^{*}\right)\right]$ with trimethylsilyl triflate has led to the isolation of a unique example of a cationic binuclear $\mathrm{Ni}(\mathrm{I})$-arene complex. All these complexes have been characterized by single-crystal X-ray, DFT, and EPR analyses, thus providing crucial experimental and theoretical information about their coordination environment and confirming a $\mathrm{d}^{9}$ electronic structure for all complexes involved. Overall, this new synthetic approach offers exciting opportunities for the discovery of new stoichiometric and catalytic reactivity as well as the mechanistic elucidation of Ni-based catalytic cycles.

\section{INTRODUCTION}

The field of catalysis has traditionally been dominated by latetransition metals such as $\mathrm{Pd}, \mathrm{Ru}, \mathrm{Rh}$, and $\mathrm{Ir}$, which have unlocked the development of many catalytic reactions that have changed everyday life. ${ }^{1-4}$ For instance, cross-coupling chemistry has been continually serving as a platform for the discovery of new drugs and fine chemicals. ${ }^{5-8}$ Recently, there has been a drive to explore more abundant elements for catalysis due to the limited availability of noble metals. ${ }^{9-11}$ Among others, nickel has shown potential to not only act as a more sustainable alternative to palladium but also enable access to new mechanistic manifolds proceeding through less common oxidation states. ${ }^{12-21}$ Nickel-catalyzed C-C and C$\mathrm{N}$ cross-couplings have often been proposed to operate under a $\mathrm{Ni}(0)-\mathrm{Ni}(\mathrm{II})$ pathway, usually with the oxidative addition of the halide or pseudo-halide as a starting point. ${ }^{22-25}$ However, recently, $\mathrm{Ni}(\mathrm{I})-\mathrm{Ni}(\mathrm{III})$ cycles have been increasingly proposed as alternative pathways (Scheme 1A). ${ }^{26-32}$ Because of the limited availability of simple, well-defined $\mathrm{Ni}(\mathrm{I})$ sources, those compounds are usually accessed in situ starting from a $\mathrm{Ni}$ (II) species and an external reductant. ${ }^{33-36}$ Unfortunately, the efficiency of this approach is highly dependent on the ligand used, thus hindering access to optimal catalytic systems and the discovery of new reactivity. Aside from the synthetic challenge, $\mathrm{Ni}(\mathrm{I})$ complexes also feature a low stability due to facile disproportionation reactions. ${ }^{37}$
The synthesis of the first $\mathrm{Ni}(\mathrm{I})$ compound was reported at the beginning of the past century by Bellucci and co-workers, but only structurally characterized many years later. ${ }^{38,39}$ This pioneer report has subsequently inspired many research groups, including Sigman, ${ }^{40}$ Tilley, ${ }^{41}$ Johnson, ${ }^{42}$ and others, ${ }^{43-54}$ to develop new protocols for the preparation of $\mathrm{Ni}(\mathrm{I})$ compounds (Scheme 1B). Interestingly, only in 2011, the first example of a fully characterized olefinic $\mathrm{Ni}(\mathrm{I})$ complex was reported by Trincado and Grützmacher. ${ }^{55}$ This complex has demonstrated remarkable efficiency in catalytic dehydrogenation. Importantly, a chelating amino-olefin ligand was crucial to stabilize this otherwise unstable class of complexes. In 2015, Krossing and co-workers reported the synthesis and characterization of a cationic $\mathrm{Ni}(\mathrm{COD})_{2}{ }^{+}$complex (Scheme 1B)..$^{56}$

Despite this recent progress, the field of nickel(I) chemistry is still in its infancy when compared to that of more common oxidation states. We believe the lack of a simple, versatile $\mathrm{Ni}(\mathrm{I})$ precursor that could be easily converted to a wide variety of

Received: April 9, 2021

Published: July 12, 2021 
Scheme 1. Context of the Work: (A) State-of-the-Art for Nickel Catalysis; (B) Previous Examples of Nickel(I) Species; (C) This Work

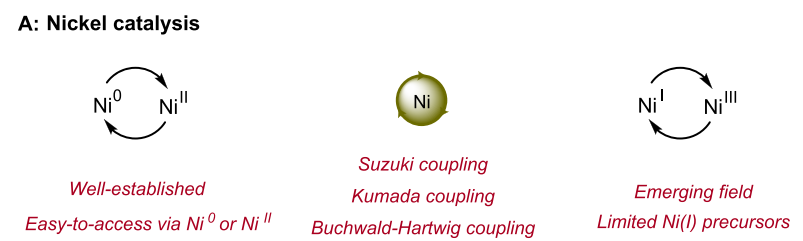

B: Previous examples of $\mathrm{Ni}(\mathrm{I})$ species

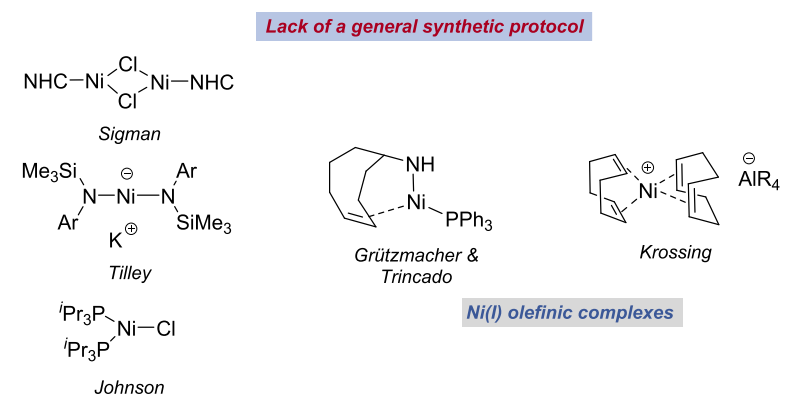

C: This work: A simple, unified route to $\mathrm{Ni}(\mathrm{l})$ species

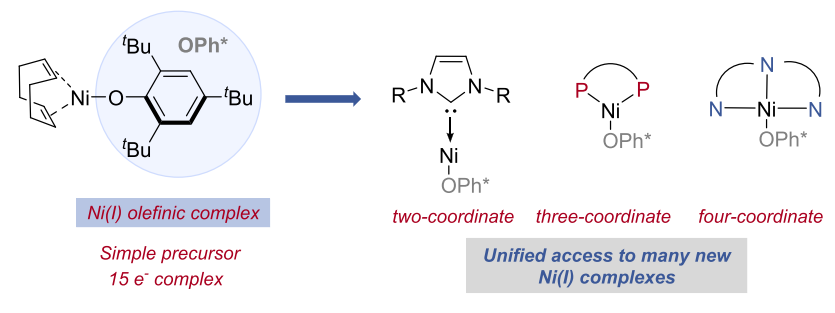

well-defined $\mathrm{Ni}(\mathrm{I})$ catalysts has hampered reaction discovery in this area. Aside from this aspect, a general route to $\mathrm{Ni}(\mathrm{I})$ complexes could also help shed light on the often-debated mechanisms in nickel catalysis. The discovery of a universal and simple route to a variety of $\mathrm{Ni}(\mathrm{I})$ species bearing a diverse set of catalytically relevant ligands would thus greatly impact organonickel chemistry and the field of catalysis.

Herein, we report the first general protocol that can mediate the formation of $\mathrm{Ni}(\mathrm{I})-\mathrm{L}$ species in good to high yields in a single step (Scheme 1C). Key to the success of this was the isolation and full characterization of a rare example of an olefinic $\mathrm{Ni}(\mathrm{I})$ complex. $^{55,56}$ This protocol can serve as a platform for synthesizing a plethora of well-defined nickel(I) complexes in a modular manner, thus promoting new research avenues in nickel chemistry.

\section{RESULTS AND DISCUSSION}

In light of the widespread use and versatility of $\mathrm{Ni}(\mathrm{COD})_{2}$ complexes as $\mathrm{Ni}(0)$ precursors, we reasoned that the synthesis of a stable $\mathrm{Ni}(\mathrm{I})$ olefin complex would be key to the development of a new platform for $\mathrm{Ni}(\mathrm{I})$ chemistry. ${ }^{55}$ Accordingly, we started our investigation through singleelectron oxidation of a $\mathrm{Ni}(0)$ precursor with heteroatom centered radicals. ${ }^{57}$ Because of the ease of undesirable overoxidation to a stable $\mathrm{Ni}(\mathrm{II})$ species, the choice of the oxidant was crucial. For instance, the reaction of $\mathrm{Ni}(\mathrm{COD})_{2}$ with TEMPO leads to a nickel(II) compound with a $\eta^{2}$ coordinate NO fragment. ${ }^{58}$ In contrast, a bulkier radical such as 2,4,6-tris-tert-butylphenoxy should efficiently avoid overoxidation due to the increased steric bulk of the resulting $\mathrm{Ni}(\mathrm{I})$ complex. ${ }^{57}$ Indeed, the reaction between $\mathrm{Ni}(\mathrm{COD})_{2}$ and the phenoxy radical (1) led to an immediate color change from blue to red with complete conversion within $2 \mathrm{~h}$ (Figure 1a).
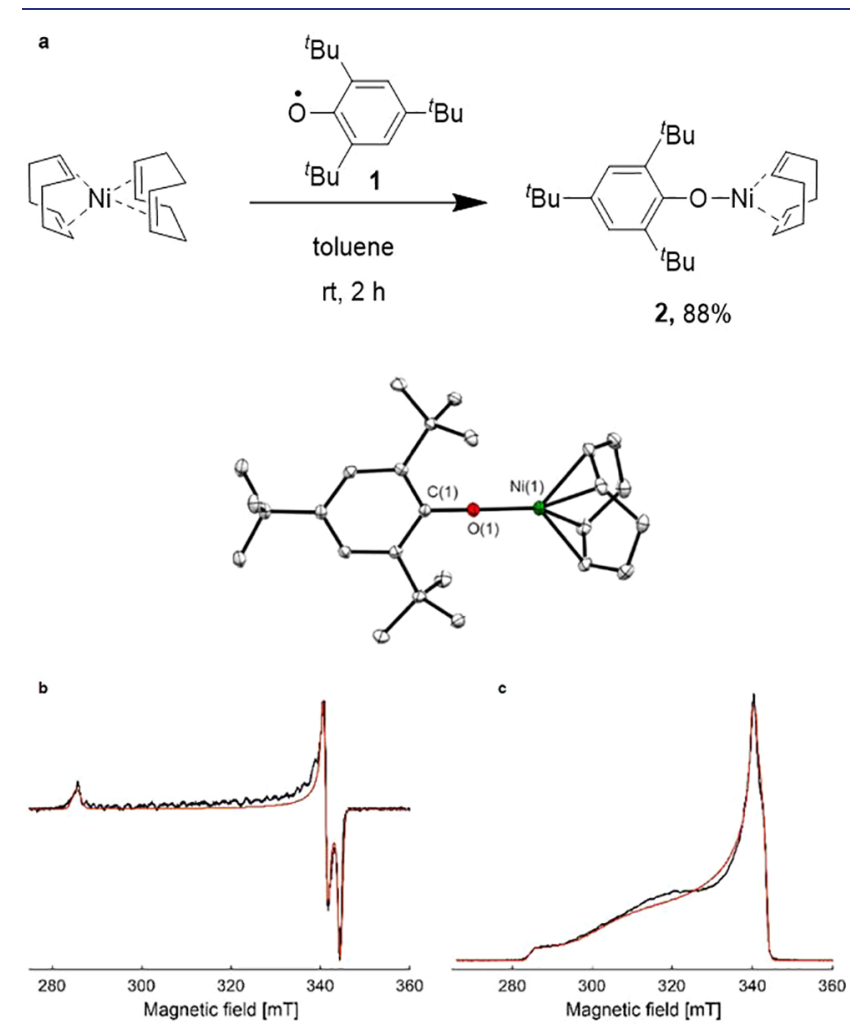

Figure 1. Synthesis and characterization of complex 2. (a) Synthesis and X-ray structure of complex 2. (b) Continuous-wave (cw) EPR spectrum of a frozen solution of complex 2 in toluene at X-band (9.74 $\mathrm{GHz}$ ) at a temperature of $20 \mathrm{~K}$ (black) and simulation (red) with $g_{x}=$ 2.0195, $g_{y}=2.0389, g_{z}=2.4363$. Experimental parameters: Microwave power $0.02 \mathrm{~mW}$; modulation amplitude: $0.1 \mathrm{mT}(100 \mathrm{kHz}$ modulation frequency); time constant $1.28 \mathrm{~ms}$. (c) Field-swept echo-detected EPR spectrum recorded at $9.73 \mathrm{GHz}, 10 \mathrm{~K}$ (black) and its simulation (red) revealing a majority component (64\%) with large $g_{z}$ strain (0.12) and with $g_{x}=2.0255, g_{y}=2.0449, g_{z}=2.3100$ together with the component $(36 \%)$ that dominates the derivative-type $\mathrm{cw}$ EPR spectrum.

Single-crystal X-ray structure analysis unambiguously confirmed the identity of this $\mathrm{Ni}(\mathrm{I})$ phenolate species. The nickel center presents a pseudo-trigonal-planar geometry with slightly elongated $\mathrm{Ni}-\mathrm{C}$ bonds compared to those of zerovalent $\mathrm{LNi}(\mathrm{COD})$ species. The strong donation of the phenolate moiety results in one of the shortest $\mathrm{Ni}-\mathrm{O}$ single bonds reported $(\mathrm{Ni}-\mathrm{O}, 1.804(1) \AA)$. Interestingly, despite the expected $\mathrm{sp}^{2}$-hybridization around the oxygen, the $\mathrm{Ni}-\mathrm{O}-$ $\mathrm{C}_{\mathrm{Ar}}$ angle is nearly linear, $179.60(9)^{\circ}$. This unusual behavior has been previously observed in other complexes and explained as a combination of electronic and crystal packing effects. ${ }^{41}$ However, we cannot rule out any distortion related to a $\mathrm{Ni}-$ COD orbital interaction. ${ }^{41}$

To gain more insights into the electronic structure of this rare example of $\mathrm{Ni}(\mathrm{I})$-olefin complex, we performed density functional theory (DFT) analysis. Single-point energy calculations were run at the PBE0 def2-QZVPP $(\mathrm{Ni}, \mathrm{P}) / \mathrm{def} 2-$ TZVPP(other atoms) level of theory by using optimized structures computed at the PBE0 def2-TZVP(Ni)/def2-SVP (other atoms) level. ${ }^{59}$ The optimized geometry reveals a similar angle $\left(\mathrm{Ni}-\mathrm{O}-\mathrm{C}_{\mathrm{Ar}}, 168.5^{\circ}\right)$ in the gas phase when 
compared to the solid-state structure, hinting at a more complicated effect than crystal packing (see the Supporting Information, Table S1). The Mulliken spin population analysis showed $90 \%$ of the spin population localized on $\mathrm{Ni}$, mainly in the d orbitals (see Table S6). This is similar to that of cationic $\mathrm{Ni}(\mathrm{COD})_{2}^{+}$and in line with previously reported metalcentered radicals. ${ }^{60}$ The $\mathrm{Ni}-\mathrm{C}_{\mathrm{COD}}$ distances, experimental and calculated, were compared to those of $\mathrm{Ni}(\mathrm{COD})_{2}{ }^{+}$, showing on average shortened bonds (see Table S1). ${ }^{56}$ This is presumably due to the higher back-donation compared to the cationic complex.

To confirm the $d^{9}$ configuration of complex 2, we performed EPR spectroscopy (Figure 1). The continuous-wave (cw) EPR spectrum of complex 2 (Figure $1 \mathrm{~b}$ ), recorded in toluene at 20 $\mathrm{K}$, revealed a slightly rhombic $g$ tensor with $g_{x}, g_{y}<g_{z}$, in line with an approximate $\left|x^{2}-y^{2}\right\rangle$ ground state of a $3 \mathrm{~d}^{9}$ species with $S=1 / 2$. The fitted principal values of the $g$ tensor $\left(g_{x}=2.020\right.$, $g_{x}=2.039$, and $\left.g_{z}=2.44\right)$ are surprisingly similar to those of $\mathrm{Ni}(\mathrm{COD})_{2}{ }^{+}\left(2.047,2.061\right.$, and 2.390). ${ }^{56}$ Schwab et al. reported a minor second component with smaller $g_{z}$ and larger $g_{z}$ strain both in frozen solution and in a powder. ${ }^{60,61}$ Because signals with large $g$ strain may go unnoticed in the derivative-mode CW EPR spectra and are better seen in absorption spectra, we acquired a field-swept echo-detected EPR spectrum at $10 \mathrm{~K}$. This spectrum (Figure 1c) showed similar values of the $g$ tensor to those of the frozen solution. ${ }^{62}$ It did, however, indeed contain a second component with smaller $g_{z}$ and larger $g_{z}$ strain that in our case turned out to be the majority component (64\%).

It is worth noting that complex $\mathbf{2}$ is a rare example of a structurally characterized $\mathrm{Ni}(\mathrm{I})$-olefin species, which have long been sought after. ${ }^{55,56}$ Interestingly, complex 2 shows higher stability both in solution and in solid phase when compared to that of halido analogues, which decompose within minutes in the absence of free COD. ${ }^{51}$ This makes complex 2 an ideal candidate to become a general source of $\mathrm{Ni}(\mathrm{I})$ in organonickel chemistry.

Once we had fully characterized complex 2 , bearing a labile alkene fragment, we wondered whether this complex could be used as a central platform for the synthesis of both established and new $\mathrm{Ni}(\mathrm{I})$ complexes bearing a broad diversity of ligands and coordination numbers. To demonstrate its versatility, we evaluated three general classes of ligands that are widely employed in catalysis: phosphine, $\mathrm{N}$-heterocyclic carbene (NHC), and pyridine. In situ generated complex 2 smoothly reacted with each ligand to generate the corresponding products in good to excellent yields (Scheme 2). Both bidentate phosphines, dcype (1,2-bis(dicyclohexylphosphino)ethane) and dppe (1,2-bis(diphenylphosphino)ethane), gave the corresponding nickel(I) species, 3 and 4 , in $81 \%$ and $89 \%$ isolated yield regardless of the change in electronics. The reaction with a monodentate NHC ligand also resulted in good yield (complex 5, 80\%), giving access to a two-coordinate 13electron compound. This unusually low coordination number is of great interest due to the high propensity of such species to undergo oxidative addition reactions. ${ }^{45}$ This class of complexes has been previously only accessed via reduction with $\mathrm{KC}_{8}$ or other strong reductants of the nickel(II) halo precursor in a multistep synthesis, clearly highlighting the unique modularity of our new synthetic approach. ${ }^{27,41,64}$ Finally, the efficiency of this protocol was also tested on a tridentate nitrogen-based ligand, terpy $\left(2,2^{\prime}: 6^{\prime}, 2^{\prime \prime}\right.$-terpyridine $)$, allowing the isolation of complex 6 in $51 \%$ yield.
Scheme 2. Syntheses of $\mathrm{Ni}(\mathrm{I})$ Complexes

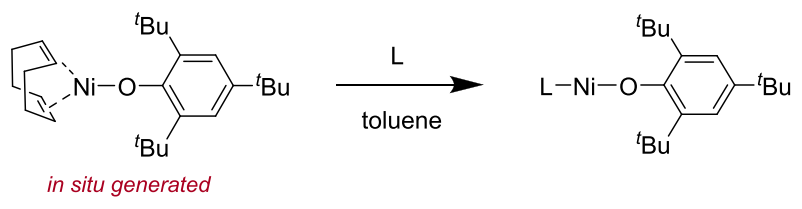

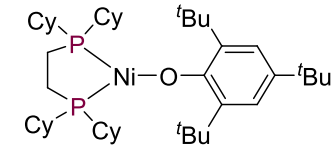

$3,81 \%$

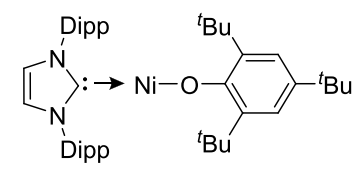

$5,80 \%$<smiles>CC(C)(C)c1cc(C(C)(C)C)c(ON2c3ccccc3P3CCN2O[PH]3(c2ccccc2)c2ccccc2)c(C(C)(C)C)c1</smiles>

4, $89 \%$

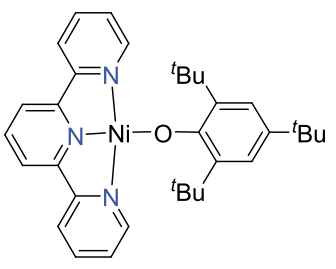

$6,51 \%$
All the complexes were structurally characterized by singlecrystal X-ray analysis (Figure 2). Complexes 3 and 4 feature a
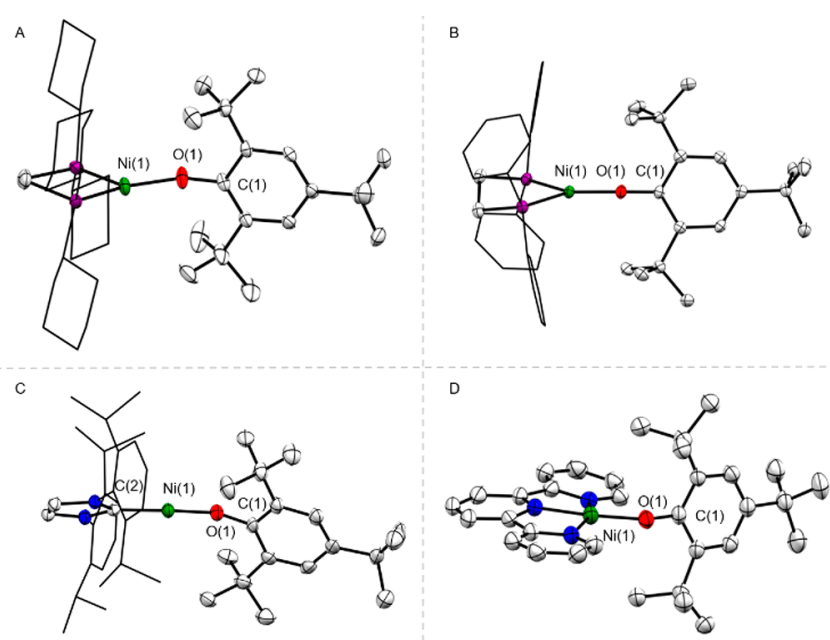

Figure 2. Molecular structures of 3 and 4 (A and B, respectively, top) and 5 and 6 ( $\mathrm{C}$ and $\mathrm{D}$, respectively, bottom) in the solid state. Ellipsoids are drawn at $50 \%$ probability; hydrogen atoms are omitted for clarity. Selected bonds and angles (four independent moieties in 5): $\mathrm{Ni}-\mathrm{O}[\AA]: 3,1.834(4) ; 4,1.808(2) ; 5,1.805(2), 1.818(3)$, $1.800(2), 1.820(3) ; 6,1.915(3) . \mathrm{C}(1)-\mathrm{O}-\mathrm{Ni}[\mathrm{deg}]: 3,164.2(9) ; 4$, 172.1(2); 5, 140.8(2), 140.9(2), 142.2(2), 138.6(2); 6, 129.7(3).

three-coordinate planar geometry with similar $\mathrm{Ni}-\mathrm{O}$ bond length (1.834(4) $\AA$ for complex 3, 1.808(2) $\AA$ for complex 4) with, however, a different $\mathrm{C}(1)-\mathrm{O}-\mathrm{Ni}$ angle $\left(164.2(9)^{\circ}\right.$ for complex 3 vs $172.1(2)^{\circ}$ for complex 4$)$. The $\mathrm{P}-\mathrm{Ni}$ bond distance and angles are in agreement with previously reported ones. ${ }^{65}$ The solid-state structure of complex 5 shows four symmetry-independent molecules in the asymmetric unit arranged in a pseudo-linear two-coordinate geometry, with an average $\mathrm{Ni}-\mathrm{O}$ bond distance of $1.81 \AA$ and an average $\mathrm{O}-\mathrm{Ni}-$ $\mathrm{C}(2)$ angle of $168.0^{\circ}$. The $\mathrm{C}(1)-\mathrm{O}-\mathrm{Ni}$ angle has an average of $140.6^{\circ}$, which is consistent with an $\mathrm{sp}^{2}$-hybridized oxygen atom and the previous example reported by Tilley and co- 
workers. $^{41}$ Complex 6 displays a distorted square-planar geometry with the phenolate ligand pointing out of the plane by $8.5(2)^{\circ}$. The $\mathrm{Ni}-\mathrm{O}$ bond length is $1.915(3) \AA$, which is elongated compared to those of complexes 3, 4, and 5 . This has been previously explained by the noninnocent behavior of the terpyridine moiety. ${ }^{21}$

Next, the geometries of the complexes were optimized, and single-point energies were calculated by DFT. ${ }^{59}$ The Mulliken spin density analysis suggested that all complexes are best described as $\mathrm{Ni}(\mathrm{I})$ species with metal-centered radicals. The smallest values were obtained for complexes $\mathbf{3}$ and $\mathbf{4}$ (both 0.81 ), possibly due to delocalization over the phosphorus atoms (see Tables S7 and S8). Complexes 5 and 6 instead showed a higher localization with predicted values of 0.93 and 1.29 , respectively (see Tables S9 and S10).

The cw EPR spectra of complexes 3 and 4 (Figure 3, a and $\mathrm{b}$, respectively) showed very similar features. The $g$ tensor

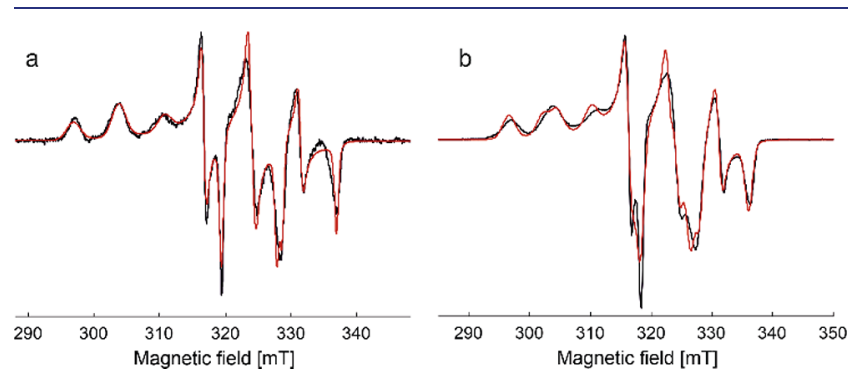

Figure 3. Continuous-wave $(\mathrm{cw})$ EPR spectra of frozen solutions of complexes 3 (a) and 4 (b) in toluene at X-band frequencies $(9.39$ $\mathrm{GHz}$ ) at $78 \mathrm{~K}$ (black) and simulations (red) assuming a rhombic $g$ tensor and anisotropic hyperfine couplings to two ${ }^{31} \mathrm{P}$ nuclei (for parameters, see Table S12). Experimental parameters: microwave power $1.616 \mathrm{~mW}(\mathrm{a}), 0.6325 \mathrm{~mW}$ (b); modulation amplitude: $0.2 \mathrm{mT}$ (100 kHz modulation frequency); time constant $1.28 \mathrm{~ms}$.

principal values agree within experimental uncertainty $\left(g_{x} \approx\right.$ 2.053, $g_{y} \approx 2.075$, and $g_{z} \approx 2.215$; see Table S12) and again reveal a $3 \mathrm{~d}^{9}$ species with $S=1 / 2$ and an approximate $\left|x^{2}-y^{2}\right\rangle$ ground state. The difference is in the ${ }^{31} \mathrm{P}$ hyperfine tensors, which are nearly axial and rather similar for the two phosphorus atoms in 3 and rhombic and rather dissimilar for the two phosphorus atoms in complex 4. This stronger deviation from a symmetric distribution around the two phosphorus atoms can be seen directly in the line shape. The symmetry breaking arises from a torsion of the $\mathrm{P}-\mathrm{Ni}-\mathrm{P}$ plane with respect to the phenyl plane of the phenolate ligand $\left(\sim 85^{\circ}\right.$ for dcype, $\sim 80^{\circ}$ for dppe) together with a tilt of the $\mathrm{P}-\mathrm{Ni}-\mathrm{P}$ angle bisector with respect to the $\mathrm{Ni}-\mathrm{O}$ bond that leads to a difference between the two $\mathrm{O}-\mathrm{Ni}-\mathrm{P}$ angles by about $7^{\circ}$ in both cases. We assign the stronger influence on the ${ }^{31} \mathrm{P}$ hyperfine couplings in the dppe case to the more facile distribution of spin density into the phenyl substituents as compared to the cyclohexyl substituents.

Unfortunately, despite repeated attempts, we were unable to obtain an EPR spectrum of complex 5 in frozen solution. We did observe weak signals of paramagnetic species in line with a $\mathrm{Ni}(\mathrm{I}) 3 \mathrm{~d}^{9}$ species, but the spectra proved to be poorly reproducible, even when preparing the solution with freshly distilled toluene and sealing the sample tube immediately. However, the paramagnetic NMR was in agreement with a previously reported analogue, ${ }^{41}$ and we obtained an EPR spectrum with the expected amplitude from the microcrystalline powder in a sealed tube (see Figure S2).
In contrast, complex 6 gave a cw EPR spectrum with the expected intensity (Figure $4 \mathrm{a}$ ) and with principal values of the
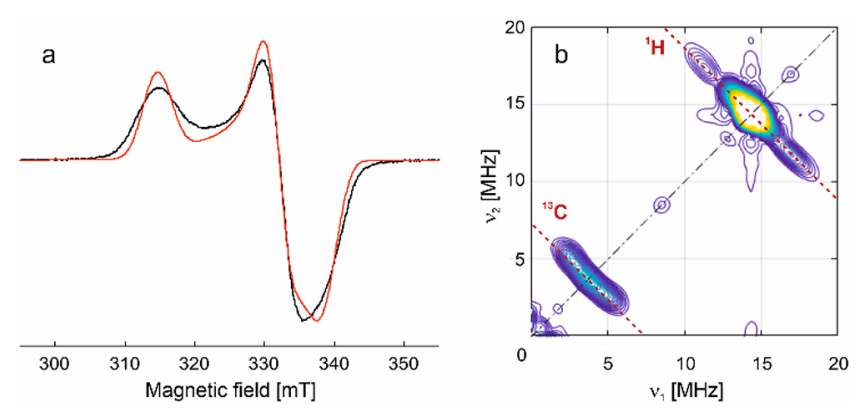

Figure 4. (a) Continuous-wave (cw) EPR spectrum of complex 6 obtained at X-band frequency $(9.68 \mathrm{GHz})$ at $78 \mathrm{~K}$. (b) HYSCORE spectrum obtained at $9.69 \mathrm{GHz}, 15 \mathrm{~K}$, and a field of $331.7 \mathrm{mT}$ of a frozen solution of complex 6 in toluene.

$g$ tensor $\left(g_{x}=2.052, g_{y}=2.090\right.$, and $\left.g_{z}=2.207\right)$ quite similar to the ones in complexes 3 and 4 and to previously reported analogues. ${ }^{66}$ The large line width in this spectrum is mainly due to unresolved hyperfine coupling on the order of 25-40 $\mathrm{MHz}$ to the three directly coordinated ${ }^{14} \mathrm{~N}$ nuclei. However, $g$ strain appears to contribute significantly, especially at $g_{z}$, also explaining the only moderate quality of the line shape fit. The $g$ tensor principal values are surprisingly similar to the ones found for $\left[\mathrm{Cu}\left(\text { tpy- } \mathrm{d}_{2}\right)_{2} \mathrm{Cl}_{2}\right]$ in ethanol- $d_{6}\left(g_{x}=2.028, g_{y}=\right.$ 2.096, and $\left.g_{z}=2.260\right)$.

The HYSCORE spectrum (Figure 4b) does not reveal the ${ }^{14} \mathrm{~N}$ hyperfine couplings that would contribute in the negative quadrant (not shown). The isotropic deuterium hyperfine coupling of $0.72 \mathrm{MHz}$ determined by $\mathrm{W}$-band ENDOR and Xband HYSCORE for the most strongly coupled $o$-deuterons in the $\left[\mathrm{Cu}\left(\text { tpy- } \mathrm{d}_{2}\right)_{2} \mathrm{Cl}_{2}\right]$ complex in 1:1 ethanol/dichloromethane translates to a proton coupling of $4.7 \mathrm{MHz}$, whereas a coupling of $5.6 \mathrm{MHz}$ can be read off the spectrum in Figure $3 b .^{67}$ Taken together, the $\mathrm{cw}$ EPR and HYSCORE spectrum indicate a rather similar electronic structure and spin density distribution in complex 6 and $\left[\mathrm{Cu}\left(\text { tpy- } \mathrm{d}_{2}\right)_{2} \mathrm{Cl}_{2}\right]$, which are both $3 \mathrm{~d}^{9}$ species with an approximate $\left|x^{2}-y^{2}\right\rangle$ ground state.

Once we had established a synthetic route for these nickel(I) species, we investigated their reactivity in catalysis. Taking inspiration from a recent work of Matsubara, ${ }^{31}$ we decided to undertake a Buchwald-Hartwig amination using 4bromobenzophenone and diphenylaniline as benchmark substrates (Scheme 3). After a preliminary optimization of

Scheme 3. Catalytic Buchwald-Hartwig Amination with Complexes 3, 4, 5, and 6

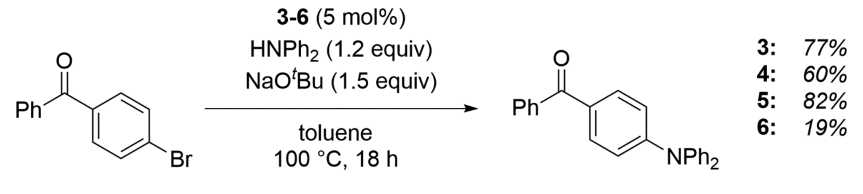

the reaction conditions, we were able to successfully perform this transformation obtaining the product in $77 \%$ isolated yield using complex 3 as the catalyst. To select the best catalytic system, we then evaluated the performance of the other complexes. Most of the complexes gave moderate to good yields with the exception of complex 6. Future work will 
evaluate the mechanism, the functional group tolerance, and versatility of this protocol.

We then wondered about the lability of the phenolate fragment, particularly whether it would be possible to extrude it to open a free coordination site and generate a highly reactive $\mathrm{Ni}(\mathrm{I})$ species. We decided to use complex 3 as a benchmark complex. Addition of $\mathrm{Me}_{3} \mathrm{SiOTf}$ to this compound in toluene gave formation of complex 7 as a red powder in more than $90 \%$ yield (Figure 5). Surprisingly, in contrast to

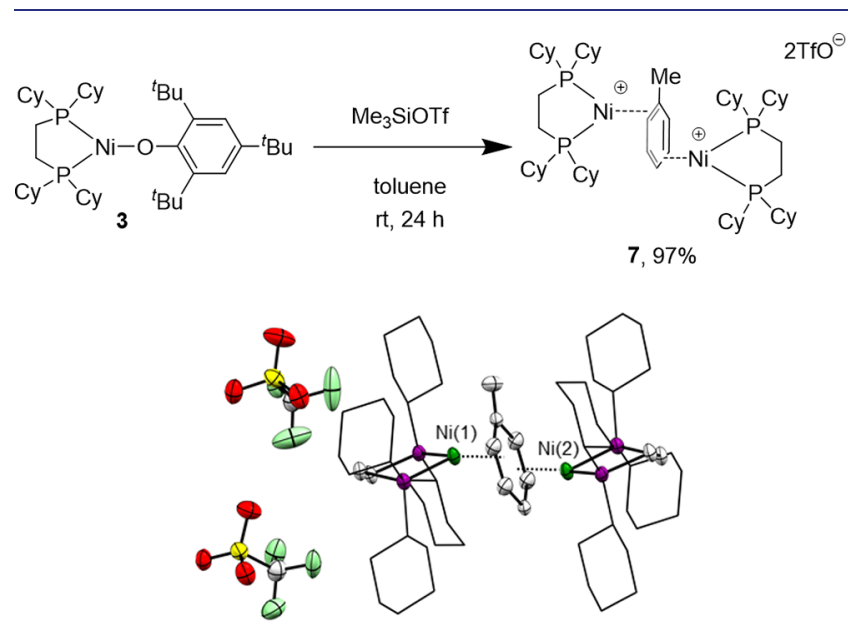

Figure 5. Synthesis and characterization of complex 7.

what has been reported by Hillhouse using 1,2-bis(di-tertbutylphosphino)ethane as ligand, we did not obtain a mononuclear nickel complex with triflate in the inner coordination sphere. ${ }^{68}$ Single-crystal X-ray analysis revealed instead this compound to be a binuclear nickel complex held together by a central coordinating toluene fragment. The two [(dcype) Ni] moieties are antifacial, with the toluene fragment plane almost perpendicular to the $\mathrm{P}-\mathrm{Ni}-\mathrm{P}$ plane. Because of disorder of the toluene fragment on a special position, precise information about the aromatic bond lengths cannot be recovered, and thus the mode of coordination remains unclear. The very short $\mathrm{Ni}-\mathrm{C}_{\mathrm{Ar}}$ distances, observed between 2.0 and $2.5 \AA$ (without further interpretation or assignment of connectivity within the disorder), hint to a potential activation of the toluene. Although a similar complex with a guanidinato ligand has been reported, this type of $\mathrm{Ni}(\mathrm{I})$-arene complex has been rarely isolated with phosphine ligands. ${ }^{69}$ We believe that this complex could be considered as a $\mathrm{Ni}(\mathrm{I})$ analogue of Pörschke's Ni(0) complex. ${ }^{70}$ The solid-state structures show in fact nearly identical geometry and $\mathrm{Ni}-\mathrm{C}_{\mathrm{Ar}}$ bond lengths, suggesting an analogous $\eta^{2}$-coordination of the aromatic fragment.

In the interest of understanding the electronic nature of this compound, we pursued DFT and EPR studies. Computational analysis revealed that the two $\mathrm{Ni}(\mathrm{I})$ centers are antiferromagnetically coupled with the broken-symmetry solution being lower in energy than the triplet state by $57 \mathrm{~kJ} / \mathrm{mol}{ }^{59}$ To further investigate, we performed solid-state EPR spectroscopy which showed only weak intensity (see Figure S3). Because of this and the absence of the expected zero-field splitting, we cannot assign this spectrum to complex 7 , which is in line with a predominant, antiferromagnetic singlet nickel(I) dimer. To gain more insight into the properties of this species, we performed EPR measurements in a frozen solution. The EPR spectrum of a shock-frozen solution in a mixture of acetonitrile and toluene (equal volume fractions) at $80 \mathrm{~K}$ corresponds to a $3 \mathrm{~d}^{9} S=1 / 2$ species with rhombic $g$ tensor and an approximate $\left|x^{2}-y^{2}\right\rangle$ ground state (see Figure S4). However, a HYSCORE spectrum reveals substantial ${ }^{14} \mathrm{~N}$ hyperfine couplings, strongly suggesting that acetonitrile replaced toluene as a ligand (see Figure S4), leading to a paramagnetic, potentially mononuclear species.

\section{CONCLUSIONS}

In summary, we have developed a new general protocol for the synthesis of challenging and novel $\mathrm{Ni}(\mathrm{I})$ compounds starting from a simple and rare example of an olefinic $\mathrm{Ni}(\mathrm{I})$ complex. Reaction of this precursor with a variety of mono-, bi-, and tridentate ligands has led to the isolation of the corresponding $\mathrm{Ni}(\mathrm{I})$ complexes. All the compounds were structurally characterized by single-crystal X-ray analysis, DFT calculations, and EPR spectroscopy to confirm a $\mathrm{d}^{9}$ electronic structure for all complexes involved. In addition, the first example of a $\mathrm{Ni}(\mathrm{I})$ analogue of Pörschke's complex has been reported. In a broader context, we anticipate that this new, versatile platform to access $\mathrm{Ni}(\mathrm{I})$ complexes will open new research avenues in nickel catalysis and will play an important role in elucidating the mechanistic relevance of $\mathrm{Ni}(\mathrm{I})$ species in catalysis.

\section{ASSOCIATED CONTENT}

\section{Supporting Information}

The Supporting Information is available free of charge at https://pubs.acs.org/doi/10.1021/jacs.1c03763.

Details of experimental and computational procedures and spectroscopic data and copies of EPR/NMR spectra (PDF)

Cartesian coordinates of the optimized structures (XYZ)

\section{Accession Codes}

CCDC 2075543-2075548 contain the supplementary crystallographic data for this paper. These data can be obtained free of charge via www.ccdc.cam.ac.uk/data_request/cif, or by emailing data_request@ccdc.cam.ac.uk, or by contacting The Cambridge Crystallographic Data Centre, 12 Union Road, Cambridge CB2 1EZ, UK; fax: +44 1223336033.

\section{AUTHOR INFORMATION}

\section{Corresponding Authors}

Gunnar Jeschke - Laboratorium für Physikalische Chemie, ETH Zürich, 8093 Zürich, Switzerland; 이이이.org/00000001-6853-8585; Email: gunnar.jeschke@

phys.chem.ethz.ch

Bill Morandi - Laboratorium für Organische Chemie, ETH Zürich, 8093 Zürich, Switzerland; ○ orcid.org/0000-00033968-1424; Email: bill.morandi@org.chem.ethz.ch

\section{Authors}

Alessandro Bismuto - Laboratorium für Organische Chemie, ETH Zürich, 8093 Zürich, Switzerland; 이이.org/00000002-5840-1144

Patrick Müller - Laboratorium für Organische Chemie, ETH Zürich, 8093 Zürich, Switzerland

Patrick Finkelstein - Laboratorium für Organische Chemie, ETH Zürich, 8093 Zürich, Switzerland

Nils Trapp - Laboratorium für Organische Chemie, ETH Zürich, 8093 Zürich, Switzerland

Complete contact information is available at:

https://pubs.acs.org/10.1021/jacs.1c03763 


\section{Author Contributions}

A.B. and P.M. contributed equally to this work.

\section{Funding}

The Swiss National Science Foundation (SNSF 184658) and ETH Zürich are acknowledged for financial support.

\section{Notes}

The authors declare no competing financial interest.

\section{ACKNOWLEDGMENTS}

We thank the NMR and X-ray departments of ETH Zürich for technical assistance. All the authors thank Dr. Michael J. Cowley for fruitful discussions. We also thank the Morandi group for proofreading.

\section{REFERENCES}

(1) Suzuki, A. Cross-Coupling Reactions of Organoboranes: An Easy Way to Construct C-C Bonds (Nobel Lecture). Angew. Chem., Int. Ed. 2011, 50 (30), 6722-6737.

(2) Ogba, O. M.; Warner, N. C.; O’Leary, D. J.; Grubbs, R. H. Recent Advances in Ruthenium-Based Olefin Metathesis. Chem. Soc. Rev. 2018, 47 (12), 4510-4544.

(3) Hartwig, J. F.; Larsen, M. A. Undirected, Homogeneous $\mathrm{C}-\mathrm{H}$ Bond Functionalization: Challenges and Opportunities. ACS Cent. Sci. 2016, 2 (5), 281-292.

(4) Franke, R.; Selent, D.; Börner, A. Applied Hydroformylation. Chem. Rev. 2012, 112 (11), 5675-5732.

(5) Corbet, J. P.; Mignani, G. Selected Patented Cross-Coupling Reaction Technologies. Chem. Rev. 2006, 106 (7), 2651-2710.

(6) Knappke, C. E. I.; Jacobi von Wangelin, A. 35 Years of Palladium-Catalyzed Cross-Coupling with Grignard Reagents: How Far Have We Come? Chem. Soc. Rev. 2011, 40 (10), 4948.

(7) Uehling, M. R.; King, R. P.; Krska, S. W.; Cernak, T.; Buchwald, S. L. Pharmaceutical Diversification via Palladium Oxidative Addition Complexes. Science 2019, 363 (6425), 405-408.

(8) Torborg, C.; Beller, M. Recent Applications of PalladiumCatalyzed Coupling Reactions in the Pharmaceutical, Agrochemical, and Fine Chemical Industries. Adv. Synth. Catal. 2009, 351 (18), 3027-3043.

(9) Su, B.; Cao, Z. C.; Shi, Z. J. Exploration of Earth-Abundant Transition Metals ( $\mathrm{Fe}, \mathrm{Co}$, and $\mathrm{Ni}$ ) as Catalysts in Unreactive Chemical Bond Activations. Acc. Chem. Res. 2015, 48 (3), 886-896.

(10) Chirik, P.; Morris, R. Getting Down to Earth: The Renaissance of Catalysis with Abundant Metals. Acc. Chem. Res. 2015, 48 (9), 2495.

(11) Yang, Z.-P.; Freas, D. J.; Fu, G. C. The Asymmetric Synthesis of Amines via Nickel-Catalyzed Enantioconvergent Substitution Reactions. J. Am. Chem. Soc. 2021, 143 (7), 2930-2937.

(12) Tasker, S. Z.; Standley, E. A.; Jamison, T. F. Recent Advances in Homogeneous Nickel Catalysis. Nature 2014, 509 (7500), 299309.

(13) Ananikov, V. P. Nickel: The "Spirited Horse" of Transition Metal Catalysis. ACS Catal. 2015, 5 (3), 1964-1971.

(14) Hazari, N.; Melvin, P. R.; Beromi, M. M. Well-Defined Nickel and Palladium Precatalysts for Cross-Coupling. Nat. Rev. Chem. 2017, 1 (3), $1-17$.

(15) Harry, N. A.; Saranya, S.; Ujwaldev, S. M.; Anilkumar, G. Recent Advances and Prospects in Nickel-Catalyzed C-H Activation. Catal. Sci. Technol. 2019, 9 (8), 1726-1743.

(16) Somerville, R. J.; Odena, C.; Obst, M. F.; Hazari, N.; Hopmann, K. H.; Martin, R. Ni(I)-Alkyl Complexes Bearing Phenanthroline Ligands: Experimental Evidence for $\mathrm{CO}_{2}$ Insertion at Ni(I) Centers. J. Am. Chem. Soc. 2020, 142 (25), 10936-10941.

(17) Day, C. S.; Somerville, R. J.; Martin, R. Deciphering the dichotomy exerted by $\mathrm{Zn}(\mathrm{ii})$ in the catalytic $\mathrm{sp}^{2} \mathrm{C}-\mathrm{O}$ bond functionalization of aryl esters at the molecular level. Nat. Catal 2021, 4 (2), 124-133.
(18) Meucci, E. A.; Ariafard, A.; Canty, A. J.; Kampf, J. W.; Sanford, M. S. Aryl-Fluoride Bond-Forming Reductive Elimination from Nickel(IV) Centers. J. Am. Chem. Soc. 2019, 141 (33), 13261-13267.

(19) Camasso, N. M.; Sanford, M. S. Design, synthesis, and carbonheteroatom coupling reactions of organometallic nickel(IV) complexes. Science 2015, 347 (6227), 1218-1220.

(20) Maher, A. G.; Liu, M.; Nocera, D. G. Ligand Noninnocence in Nickel Porphyrins: Nickel Isobacteriochlorin Formation under Hydrogen Evolution Conditions. Inorg. Chem. 2019, 58 (12), 7958-7968.

(21) Wagner, C. L.; Herrera, G.; Lin, Q.; Hu, C. T.; Diao, T. Redox Activity of Pyridine-Oxazoline Ligands in the Stabilization of LowValent Organonickel Radical Complexes. J. Am. Chem. Soc. 2021, 143 (14), 5295-5300.

(22) Zell, T.; Fischer, P.; Schmidt, D.; Radius, U. C-Br Activation of Aryl Bromides at $\mathrm{Ni}^{\mathrm{O}}(\mathrm{NHC})_{2}$ : Stoichiometric Reactions, Catalytic Application in Suzuki-Miyaura Cross-Coupling, and Catalyst Degradation. Organometallics 2012, 31 (14), 5065-5073.

(23) Desnoyer, A. N.; Love, J. A. Recent Advances Well-Defined, Late Transition Metal Complexes That Make and/or Break C-N, C-O and C-S Bonds. Chem. Soc. Rev. 2017, 46 (1), 197-238.

(24) Campeau, L. C.; Hazari, N. Cross-Coupling and Related Reactions: Connecting Past Success to the Development of New Reactions for the Future. Organometallics 2019, 38 (1), 3-35.

(25) Bismuto, A.; Delcaillau, T.; Müller, P.; Morandi, B. NickelCatalyzed Amination of Aryl Thioethers: A Combined Synthetic and Mechanistic Study. ACS Catal. 2020, 10 (8), 4630-4639.

(26) Cornella, J.; Gómez-Bengoa, E.; Martin, R. Combined Experimental and Theoretical Study on the Reductive Cleavage of Inert C-O Bonds with Silanes: Ruling out a Classical $\mathrm{Ni}(0) / \mathrm{Ni}(\mathrm{II})$ Catalytic Couple and Evidence for $\mathrm{Ni}(\mathrm{I})$ Intermediates. J. Am. Chem. Soc. 2013, 135 (5), 1997-2009.

(27) Lipschutz, M. I.; Tilley, T. D. Carbon-Carbon Cross-Coupling Reactions Catalyzed by a Two-Coordinate Nickel(II)-Bis(Amido) Complex via Observable Ni I, Ni II, and Ni III Intermediates. Angew. Chem., Int. Ed. 2014, 53 (28), 7290-7294.

(28) Matsubara, K.; Fukahori, Y.; Inatomi, T.; Tazaki, S.; Yamada, Y.; Koga, Y.; Kanegawa, S.; Nakamura, T. Monomeric ThreeCoordinate N-Heterocyclic Carbene Nickel(I) Complexes: Synthesis, Structures, and Catalytic Applications in Cross-Coupling Reactions. Organometallics 2016, 35 (19), 3281-3287.

(29) Lavoie, C. M.; McDonald, R.; Johnson, E. R.; Stradiotto, M. Bisphosphine-Ligated Nickel Pre-Catalysts in $\mathrm{C}\left(\mathrm{sp}^{2}\right)-\mathrm{N}$ CrossCouplings of Aryl Chlorides: A Comparison of Nickel(I) and Nickel(II). Adv. Synth. Catal. 2017, 359 (17), 2972-2980.

(30) Pandey, D. K.; Ankade, S. B.; Ali, A.; Vinod, C. P.; Punji, B. Nickel-Catalyzed C-H Alkylation of Indoles with Unactivated Alkyl Chlorides: Evidence of a $\mathrm{Ni}(\mathrm{i}) / \mathrm{Ni}(\mathrm{Iii})$ Pathway. Chem. Sci. 2019, 10 (41), 9493-9500.

(31) Inatomi, T.; Fukahori, Y.; Yamada, Y.; Ishikawa, R.; Kanegawa, S.; Koga, Y.; Matsubara, K. Ni(I)-Ni(III) Cycle in BuchwaldHartwig Amination of Aryl Bromide Mediated by NHC-Ligated Ni(I) Complexes. Catal. Sci. Technol. 2019, 9 (8), 1784-1793.

(32) Yin, G.; Kalvet, I.; Englert, U.; Schoenebeck, F. Fundamental Studies and Development of Nickel-Catalyzed Trifluoromethylthiolation of Aryl Chlorides: Active Catalytic Species and Key Roles of Ligand and Traceless MeCN Additive Revealed. J. Am. Chem. Soc. 2015, 137 (12), 4164-4172.

(33) Jouffroy, M.; Kelly, C. B.; Molander, G. A. Thioetherification via Photoredox/Nickel Dual Catalysis. Org. Lett. 2016, 18 (4), 876879.

(34) Arendt, K. M.; Doyle, A. G. Dialkyl Ether Formation by NickelCatalyzed Cross-Coupling of Acetals and Aryl Iodides. Angew. Chem., Int. Ed. 2015, 54 (34), 9876-9880.

(35) Woods, B. P.; Orlandi, M.; Huang, C. Y.; Sigman, M. S.; Doyle, A. G. Nickel-Catalyzed Enantioselective Reductive Cross-Coupling of Styrenyl Aziridines. J. Am. Chem. Soc. 2017, 139 (16), 5688-5691. 
(36) Fang, Y.; Rogge, T.; Ackermann, L.; Wang, S.-Y.; Ji, S.-J. NickelCatalyzed Reductive Thiolation and Selenylation of Unactivated Alkyl Bromides. Nat. Commun. 2018, 9 (1), 2240.

(37) Beattie, D. D.; Lascoumettes, G.; Kennepohl, P.; Love, J. A.; Schafer, L. L. Disproportionation Reactions of an Organometallic $\mathrm{Ni}(\mathrm{I})$ Amidate Complex: Scope and Mechanistic Investigations. Organometallics 2018, 37 (9), 1392-1399.

(38) Bellucci, I.; Corelli, R. Verbindungen Des Einwertigen Nickels. Z. Anorg. Chem. 1914, 86 (1), 88-104.

(39) Jarchow, O. Die Kristallstruktur von RubidiumHexacyanodiniccolat(I). Z. Anorg. Allg. Chem. 1971, 383 (1), 40-48.

(40) Dible, B. R.; Sigman, M. S.; Arif, A. M. Oxygen-Induced Ligand Dehydrogenation of a Planar Bis- $\mu$-Chloronickel(I) Dimer Featuring an NHC Ligand. Inorg. Chem. 2005, 44 (11), 3774-3776.

(41) Lipschutz, M. I.; Tilley, T. D. Useful Method for the Preparation of Low-Coordinate Nickel(I) Complexes via Transformations of the $\mathrm{Ni}(\mathrm{I}) \mathrm{Bis}\left(\right.$ Amido) Complex $\mathrm{K}\left\{\mathrm{Ni}\left[\mathrm{N}\left(\mathrm{SiMe}_{3}\right)(2,6-\right.\right.$

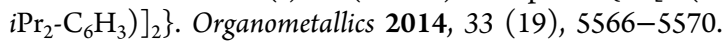

(42) Beck, R.; Shoshani, M.; Krasinkiewicz, J.; Hatnean, J. A.; Johnson, S. A. Synthesis and Chemistry of Bis(Triisopropylphosphine) Nickel(I) and Nickel(0) Precursors. Dalt. Trans. 2013, 42 (5), 1461-1475.

(43) Mohadjer Beromi, M.; Banerjee, G.; Brudvig, G. W.; Hazari, N.; Mercado, B. Q. Nickel(I) Aryl Species: Synthesis, Properties, and Catalytic Activity. ACS Catal. 2018, 8 (3), 2526-2533.

(44) MacBeth, C. E.; Thomas, J. C.; Betley, T. A.; Peters, J. C. The Coordination Chemistry of " $\left[\mathrm{BP}_{3}\right] \mathrm{NiX}$ " Platforms: Targeting LowValent Nickel Sources as Promising Candidates to $\mathrm{L}_{3} \mathrm{NiE}$ and $\mathrm{L}_{3} \mathrm{Ni}$ : $\mathrm{E}$ Linkages. Inorg. Chem. 2004, 43 (15), 4645-4662.

(45) Lin, C.-Y.; Power, P. P. Complexes of Ni(I): A "Rare" Oxidation State of Growing Importance. Chem. Soc. Rev. 2017, 46 (17), 5347-5399.

(46) Dong, Y.; Lund, C. J.; Porter, G. J.; Clarke, R. M.; Zheng, S.-L.; Cundari, T. R; Betley, T. A. Enantioselective C-H Amination Catalyzed by Nickel Iminyl Complexes Supported by Anionic Bisoxazoline (BOX) Ligands. J. Am. Chem. Soc. 2021, 143 (2), 817-829.

(47) Chakraborty, U.; Mühldorf, B.; Van Velzen, N. J. C.; De Bruin, B.; Harder, S.; Wolf, R. [CpArNi $\{\mathrm{Ga}(\mathrm{Nacnac})\}]$ : An Open-Shell Nickel(I) Complex Supported by a Gallium(I) Carbenoid (CpAr = $\left.\mathrm{C} 5\left(\mathrm{C}_{6} \mathrm{H}_{4^{-}}-\mathrm{Et}\right)_{5}, \mathrm{Nacnac}=\mathrm{HC}\left[\mathrm{C}(\mathrm{Me}) \mathrm{N}-\left(\mathrm{C}_{6} \mathrm{H}_{3}\right)-2,6-\mathrm{IPr}_{2}\right]_{2}\right)$. Inorg. Chem. 2016, 55 (6), 3075-3078.

(48) Pelties, S.; Herrmann, D.; de Bruin, B.; Hartl, F.; Wolf, R. Selective P4 Activation by an Organometallic Nickel(i) Radical: Formation of a Dinuclear Nickel(Ii) Tetraphosphide and Related Diand Trichalcogenides. Chem. Commun. 2014, 50 (53), 7014-7016.

(49) Hierlmeier, G.; Coburger, P.; Leest, N. P.; Bruin, B.; Wolf, R. Aggregation and Degradation of White Phosphorus Mediated by NHeterocyclic Carbene Nickel(0) Complexes. Angew. Chem., Int. Ed. 2020, 59 (33), 14148-14153.

(50) Jongbloed, L. S.; Vogt, N.; Sandleben, A.; de Bruin, B.; Klein, A.; van der Vlugt, J. I. Nickel-Alkyl Complexes with a Reactive PNCPincer Ligand. Eur. J. Inorg. Chem. 2018, 2018 (20), 2408-2418.

(51) Dong, Y.; Lukens, J. T.; Clarke, R. M.; Zheng, S. L.; Lancaster, K. M.; Betley, T. A. Synthesis, Characterization and C-H Amination Reactivity of Nickel Iminyl Complexes. Chem. Sci. 2020, 11 (5), $1260-1268$

(52) Dong, Y.; Clarke, R. M.; Porter, G. J.; Betley, T. A. Efficient C$\mathrm{H}$ Amination Catalysis Using Nickel-Dipyrrin Complexes. J. Am. Chem. Soc. 2020, 142 (25), 10996-11005.

(53) Beck, R.; Shoshani, M.; Krasinkiewicz, J.; Hatnean, J. A.; Johnson, S. A. Synthesis and Chemistry of Bis(Triisopropylphosphine) Nickel(I) and Nickel(0) Precursors. Dalt. Trans. 2013, 42 (5), 1461-1475.

(54) Horn, B.; Limberg, C.; Herwig, C.; Braun, B. Three-Coordinate Nickel(II) and Nickel(I) Thiolate Complexes Based on the $\beta$ Diketiminate Ligand System. Inorg. Chem. 2014, 53 (13), 6867-6874.
(55) Vogt, M.; de Bruin, B.; Berke, H.; Trincado, M.; Grützmacher, H. Amino Olefin Nickel(I) and Nickel(0) Complexes as Dehydrogenation Catalysts for Amine Boranes. Chem. Sci. 2011, 2 (4), 723.

(56) Schwab, M. M.; Himmel, D.; Kacprzak, S.; Kratzert, D.; Radtke, V.; Weis, P.; Ray, K.; Scheidt, E. W.; Scherer, W.; De Bruin, B.; Weber, S.; Krossing, I. $\left[\mathrm{Ni}(\mathrm{Cod})_{2}\right]\left[\mathrm{Al}(\mathrm{ORF})_{4}\right]$, a Source for Naked Nickel(I) Chemistry. Angew. Chem., Int. Ed. 2015, 54 (49), 1470614709 .

(57) Schott, A.; Schott, H.; Wilke, G.; Brandt, J.; Hoberg, H.; Hoffmann, E. G. Übergangsmetall-Komplexe, II1) Reaktionen von Nickel(0) Mit Radikalen. Justus Liebigs Ann. Chem. 1973, 1973 (3), $508-530$

(58) Isrow, D.; Captain, B. Synthesis and Reactivity of a Transition Metal Complex Containing Exclusively TEMPO Ligands: $\mathrm{Ni}\left(\eta^{2}\right.$ TEMPO) $)_{2}$ Inorg. Chem. 2011, 50 (13), 5864-5866.

(59) Please see the Supporting Information for further details.

(60) Schwab, M. M.; Himmel, D.; Kacprzak, S.; Yassine, Z.; Kratzert, D.; Felbek, C.; Weber, S.; Krossing, I. Isolated Cationic Organometallic Nickel(I) Arene Complexes. Eur. J. Inorg. Chem. 2019, 2019 (28), 3309-3317.

(61) In an earlier cw EPR measurement with larger modulation amplitude, where the compound was slightly contaminated with 1 , we had noticed a much broader feature at $g_{z} \sim 2.3$.

(62) This spectrum can be simulated as a superposition of the component seen by cw EPR (36\%) and a majority component (64\%) with $g_{x}=2.026, g_{y}=2.045, g_{z}=2.310$, and large $g_{z}$ strain (0.120).

(63) Porri, L.; Vitulli, G.; Gallazzi, M. C. 1,5-Cyclooctadien-NickelBromid Und -Jodid. Angew. Chem. 1967, 79 (9), 414-414.

(64) Borys, A. M.; Hevia, E. Beyond Ni\{N(SiMe3)2\}2: Synthesis of a Stable Solvated Sodium Tris-Amido Nickelate. Organometallics 2021, 40 (3), 442-447.

(65) Kitiachvili, K. D.; Mindiola, D. J.; Hillhouse, G. L. Preparation of Stable Alkyl Complexes of $\mathrm{Ni}(\mathrm{I})$ and Their One-Electron Oxidation to Ni(II) Complex Cations. J. Am. Chem. Soc. 2004, 126 (34), 10554-10555.

(66) Ciszewski, J. T.; Mikhaylov, D. Y.; Holin, K. V.; Kadirov, M. K.; Budnikova, Y. H.; Sinyashin, O.; Vicic, D. A. Redox Trends in Terpyridine Nickel Complexes. Inorg. Chem. 2011, 50 (17), 86308635.

(67) Narr, E.; Zimmermann, H.; Godt, A.; Goldfarb, D.; Jeschke, G. Structure and Dynamics of Copper Complexes with $2,2^{\prime}: 6^{\prime}, 2^{\prime \prime}$ Terpyridines in Glassy Matrices. Phys. Chem. Chem. Phys. 2003, 5 (18), 3959-3967.

(68) Iluc, V. M.; Miller, A. J. M.; Hillhouse, G. L. Synthesis and characterization of side-bound aryldiazo and end-bound nitrosyl complexes of nickel. Chem. Commun. 2005, 863 (40), 5091-5093.

(69) Jones, C.; Schulten, C.; Fohlmeister, L.; Stasch, A.; Murray, K. S.; Moubaraki, B.; Kohl, S.; Ertem, M. Z.; Gagliardi, L.; Cramer, C. J. Bulky Guanidinato Nickel(I) Complexes: Synthesis, Characterization, Isomerization, and Reactivity Studies. Chem. - Eur. J. 2011, 17 (4), 1294-1303.

(70) Bach, I.; Pörschke, K.-R.; Goddard, R.; Kopiske, C.; Krüger, C.; Rufińska, A.; Seevogel, K. Synthesis, Structure, and Properties of $\left\{\left({ }^{\mathrm{t}} \mathrm{Bu}_{2} \mathrm{PC}_{2} \mathrm{H}_{4} \mathrm{P}^{\mathrm{t}} \mathrm{Bu}_{2}\right) \mathrm{Ni}\right\}_{2}\left(\mu-\eta \quad 2: \eta 2-\mathrm{C}_{6} \mathrm{H}_{6}\right)$ and $\left({ }^{\mathrm{t}} \mathrm{Bu}_{2} \mathrm{PC}_{2} \mathrm{H}_{4} \mathrm{PtBu}_{2}\right)$ $\mathrm{Ni}\left(\eta 2-\mathrm{C}_{6} \mathrm{~F}_{6}\right)$. Organometallics 1996, 15 (23), 4959-4966. 